\title{
PENGARUH FAKTOR-FAKTOR FUNDAMENTAL DAN KEPEMILIKAN INSTITUSIONAL TERHADAP HARGA SAHAM SEKTOR INFRASTRUKTUR, UTILITAS, DAN TRANSPORTASI YANG TERDAFTAR DI BURSA EFEK INDONESIA
}

\author{
Kamilia Alshifa \\ Fakultas Ekonomi dan Bisnis Universitas Pancasila, Jakarta \\ J1. Raya Lenteng Agung No. 56-80, Jakarta Selatan 12640, DKI Jakarta \\ Kamilia.alshifa@gmail.com
}

\begin{abstract}
ABSTRAK
Penelitian ini bertujuan untuk menganalisis pengaruh Earning per Share (EPS), Debt to Equity Ratio (DER), Price to Book Value (PBV), dan Kepemilikan Institusional (KI) terhadap Harga Saham pada perusahaan infrastruktur, utilitas, dan transportasi pada tahun 2014-2018. Sampel penelitian diambil secara purposive sampling. Analisis yang digunakan yaitu analisis regresi data panel dengan menggunakan program Eviews versi 9. Hasil penelitian menunjukkan bahwa secara parsial, Earning per Share (EPS) dan Price to Book Value (PBV) berpengaruh signifikan terhadap harga saham, sedangkan, Debt to Equity Ratio (DER) dan Kepemilikan Institusional (KI) tidak berpengaruh signifikan terhadap harga saham. Secara simultan, seluruh variabel secara bersama-sama memiliki pengaruh yang signifikan terhadap harga saham. Koefisien determinasi yang ditunjukkan dari nilai adjusted R-square sebesar 0,4825. Hal ini berarti bahwa sebesar 48,25\% variabel dependen dapat dijelaskan oleh empat variabel independen, sedangkan sisanya sebesar $51,75 \%$ dijelaskan oleh faktor lain di luar model penelitian ini.
\end{abstract}

Kata kunci : Earning per Share (EPS), Debt to Equity Ratio (DER), Price to Book Value (PBV), dan Kepemilikan Institusional (KI) terhadap Harga Saham

\section{ABSTRACT:}

This research aimed to analyze the effect of Earning per Share (EPS), Debt to Equity Ratio (DER), Price to Book Value (PBV), and Institusional Ownership (KI) on Stock Price of infrastructure, utility, and transportation companies in 2014-2018. Sampling was done by using purposive sampling method. Analysis used is panel data regression analysis using Eviews program version 9. The results show that in partially, Earning per Share (EPS) and Price to Book Value (PBV) have significantly affected on stock price, whereas Debt to Equity Ratio (DER) and Institusional Ownership (KI) have no significantly affected on stock price. Simultaneously, all the variables together have significantly affected on stock price. The coefficient of determination shown from adjusted $R$-Squared value of 0,4825. This means that the dependent variabel is 48,25\% can be explained by the four independent variables, while the remaining $51,75 \%$ is explained by other factor outside this research model.

Keywords : Earning per Share (EPS), Debt to Equity Ratio (DER), Price to Book Value (PBV), Institusional Ownership (KI), Stock Price 


\section{PENDAHULUAN}

Berbagai macam resiko yang timbul dari ketidakpastian dalam melakukan investasi harus dihadapi oleh para investor. Oleh karena hal tersebut, para investor perlu mengetahui informasi yang lengkap agar dapat meminimalisir atau bahkan menghindari berbagai macam resiko tersebut. Pada dasarnya, tingkat keuntungan dan tingkat resiko berbanding lurus. Semakin tinggi tingkat keuntungan yang diharapkan, maka tingkat resiko yang akan ditanggung juga tinggi. Pasar modal merupakan tempat pertemuan antara penawaran dan permintaan surat berharga dimana para pelaku pasar, yaitu individu-individu atau badan usaha yang memiliki kelebihan dana (surplus funds) melakukan investasi dalam surat berharga yang ditawarkan oleh emiten. Sebaliknya, perusahaan (entities) yang membutuhkan dana menawarkan surat berharga dengan cara listing terlebih dahulu pada badan otoritas di pasar modal sebagai emiten (Sunariyah, 2011: 5).

Sebelum membeli saham, investor tidak begitu saja membeli saham perusahaan tersebut, tetapi akan melakukan penilaian terlebih dahulu terhadap saham perusahaan dengan melakukan analisis fundamental. Dalam melakukan analisis secara fundamental, investor dapat menganalisis perusahaan yang layak untuk dijadikan alternatif investasi, memilih saham perusahaan yan harga pasarnya lebih rendah dari nilai intrinsik sehingga layak dibeli, dan memilih saham perusahaan yang harga pasarnya lebih tinggi dari nilai intrinsic sehingga menguntungkan untuk dijual (tandelilin, 2010: 363).

Dalam melakukan investasi, investor perlu memperhatikan kenaikan atau penurunan harga saham yang terjadi pada perusahaan sektor infrastruktur, utilities, dan transportasi yang terdaftar di Bursa Efek Indonesia mulai dari tahun 2014-2018, adalah sebagai berikut :

\section{Gambar 1.1}

Rata - rata harga saham perusahaan sektor infrastruktur, utilities, dan transportasi

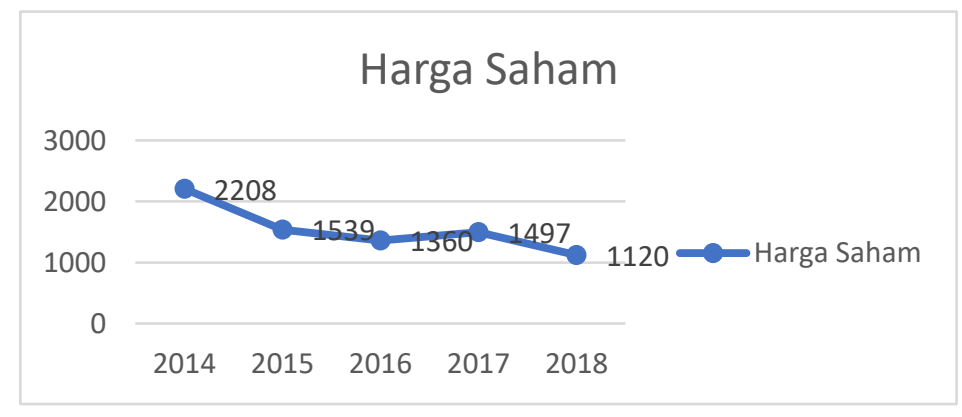

Sumber: Data diolah 
Dari gambar 1.1 dapat diketahui bahwa nilai rata-rata harga saham dari tahun 2014-2018 mengalami fluktuasi pada perusahaan-perusahaan tersebut. Fluktuasi harga saham tersebut dipengaruhi oleh banyak faktor yang terkait antara lain: profitabilitas, solvabilitas, nilai buku, dan kepemilikan institusional.

Beberapa penelitian terdahulu yang meneliti pengaruh faktor-faktor fundamental keuangan perusahaan dan kepemilikan institusional terhadap harga saham memberikan hasil yang berbeda-beda. Seperti penelitian yang dilakukan oleh Jiwandono (2014), dan Kusuma (2012) menyatakan bahwa variable Earning per Share (EPS) berpengaruh signifikan terhadap harga saham. Penelitian ini bertolak belakang dengan penelitian Zen (2009) menyatakan bahwa variabel Earning per Share (EPS) tidak mempunyai pengaruh yang signifikan terhadap harga saham. Variabel Debt to Equity Ratio (DER) terhadap harga saham menyatakan bahwa berpengaruh signifikan terhadap harga saham yang ditunjukan pada penelitian Akramunnas (2017). Hasil penelitian berbeda di tunjukan oleh penelitian Ramdhani (2013) dan Yuliandhari (2015) menyatakan bahwa Debt to Equity Ratio (DER) tidak mempunyai pengaruh yang signifikan terhadap harga saham. Pada penelitian yang dilakukan oleh Yuliawati (2015), dan Sari (2016) menyatakan bahwa variabel Price to Book value (PBV) memiliki pengaruh yang signifikan terhadap harga saham. Sedangkan penelitian yang dilakukan oleh Sha (2015) menunjukan bahwa variabel Price to Book value (PBV) tidak memiiki pengaruh yang signifikan terhadap harga saham. Pada penelitian yang dilakukan oeh Joyo (2015) mengenai pengaruh antara kepemilikan institusional terhadap harga saham menunjukan bahwa memiliki pengaruh yang signifikan terhadap harga saham. Hasil penelitian berbeda ditunjukan oleh penelitian Nuraeni (2012) dan Reny (2018) menyatakan bahwa Kepemilikan Institusional tidak mempunyai pengaruh yang signifikan terhadap harga saham.

\section{KAJIAN TEORI}

\section{Signaling Theory}

Signaling theory adalah teori yang membahas tentang naik turunnya harga di pasar, sehingga akan memberi pengaruh pada keputusan investor. Tanggapan para investor terhadap sinyal positif dan negatif adalah sangat mempengaruhi kondisi pasar, mereka akan bereaksi dengan berbagai cara dalam menanggapi sinyal tersebut, seperti memburu saham yang dijual atau melakukan tindakan dalam bentuk tidak bereaksi seperti "lihat dan tunggu" perkembangan yang ada, baru kemudian mengambil tindakan. Keputusan tersebut bukanlah sesuatu yang salah 
namun itu dilihat sebagai reaksi investor untuk menghindari timbulnya risiko yang lebih besar karena faktor pasar yang belum memberi keuntungan atau berpihak kepadanya (Fahmi, 2012: 103).

\section{Agency Theory}

Dalam perekonomian modern, manajemen, dan pengelolaan perusahaan semakin banyak dipisahkan dari kepemilikan perusahaan. Hal ini sejalan dengan Agency Theory yang menekankan pentingnya pemilik perusahaan (pemegang saham) menyerahkan pengelolaan perusahaan kepada tenaga-tenga profesional (agents) yang lebih mengerti dalam menjalankan bisnis sehari-hari. Tujuan dari dipisahkannya pengelolaan dari kepemilikan perusahaan, yaitu agar pemilik perusahaan memperoleh keuntungan yang semaksimal mungkin dengan biaya yang seefisien mungkin. Para tenaga-tenaga profesional, bertugas untuk kepentingan perusahaan dan memiliki keleluasaan dalam menjalankan manajemen perusahaan, sehingga dalam hal ini para profesional tersebut berperan sebagai agents-nya pemegang saham. Semakin besar perusahaan yang dikelola memperoleh laba semakin besar pula keuntungan yang didapatkan agents. Sementara pemilik perusahaan (pemegang saham) hanya bertugas mengawasi dan memonitor jalannya perusahaan yang dikelola oleh manajemen untuk memastikan bahwa mereka bekerja demi kepentingan perusahaan (Sutedi,2011: 13).

\section{Harga Saham}

Harga saham adalah harga suatu saham yang terjadi di pasar bursa pada saat tertentu yang ditentukan oleh pelaku pasar dan ditentukan oleh permintaan dan penawaran saham yang bersangkutan di pasar modal (Jogiyanto, 2008: 167).

\section{Analisis Fundamental}

Analisis fundamental merupakan teknik analisis saham yang mempelajari tentang keuangan mendasar pada fakta ekonomi dari perusahaan sebagai langkah penilaian saham perusahaan (Zulfikar, 2016: 159). Analisis ini akan membandingkan nilai intrinsik suatu saham dengan harga pasarnya guna menentukan apakah harga saham tersebut sudah mencerminkan nilai intrinsiknya atau belum. Nilai intrinsik suatu saham ditentukan oleh faktor-faktor fundamental yang mempengaruhinya (Halim, 2018: 30).

\section{Earning per Share (EPS)}

Earning per share (EPS) adalah laba bersih setelah bunga dan pajak yang siap dibagikan kepada pemegang saham dibagi dengan jumlah lembar saham perusahaan (Tandelilin, 2010: 373). Pada umunya para pemegang saham tertarik dengan Earning per Share (EPS) yang besar 
karena hal tersebut merupakan salah satu indikator keberhasilan perusahaan (Syamsudin, 2009:66).

\section{Debt to Equity Ratio (DER)}

Analisis Debt to Equity Ratio (DER) berfungsi untuk mengukur seberapa besar perusahaan dibiyai dengan hutang. Dengan rasio ini maka kita dapat mengukur seberapa besar kemampuan perusahaan melunasi hutangnya (Siswoyo, 2013: 47).Debt to Equity Ratio (DER) yang tinggi akan membebankan perusahaan pada biaya bunga yang tinggi. Tingginya biaya bunga yang harus dibayar oleh perusahaan akan berdampak pada penurunan laba perusahaan. Sebaliknya, Debt to Equity Ratio (DER) yang rendah berarti biaya bunga yang dibayarkan oleh perusahaan juga rendah sehingga laba perusahaan akan meningkat yang akan berpengaruh pada pertumbuhan laba perusahaan (Fahmi, 2012: 128).

\section{Price to book value (PBV)}

Price to Book value (PBV) merupakan rasio yang menunjukkan hasil perbandingan antara harga pasar per lembar saham dengan nilai buku per lembar saham. Semakin rendah niai Price to Book value (PBV) suatu saham maka saham tersebut dikategorikan undervalued, di mana sangat baik untuk investasi jangka Panjang. Namun, rendahnya nilai Price to Book value (PBV) juga dapat mengindikasikan menurunnya kualitas dan kinerja fundamental emiten (Hery, 2014: 145).

\section{Kepemilikan Institusional}

Kepemilikan Institusional merupakan proporsi kepemilikan saham oleh institusi seperti LSM, perusahaan swasta, perusahaan efek, dana pension, perusahaan asuransi, bank, dan perusahaan-perusahaan investasi. Kepemilikan institusional diukur dengan menggunakan rasio antara jumlah lembar saham yang dimiliki oleh institusi terhadap jumlah lembar saham perusahaan yang beredar secara keseluruhan (Nugrahanti, 2013: 9).

\section{Kerangka Pemikiran}

Secara sistematis kerangka pemikiran dalam penelitian ini dapat dilihat pada gambar berikut ini : 


\section{Gambar 2.1 \\ Kerangka pemikiran}

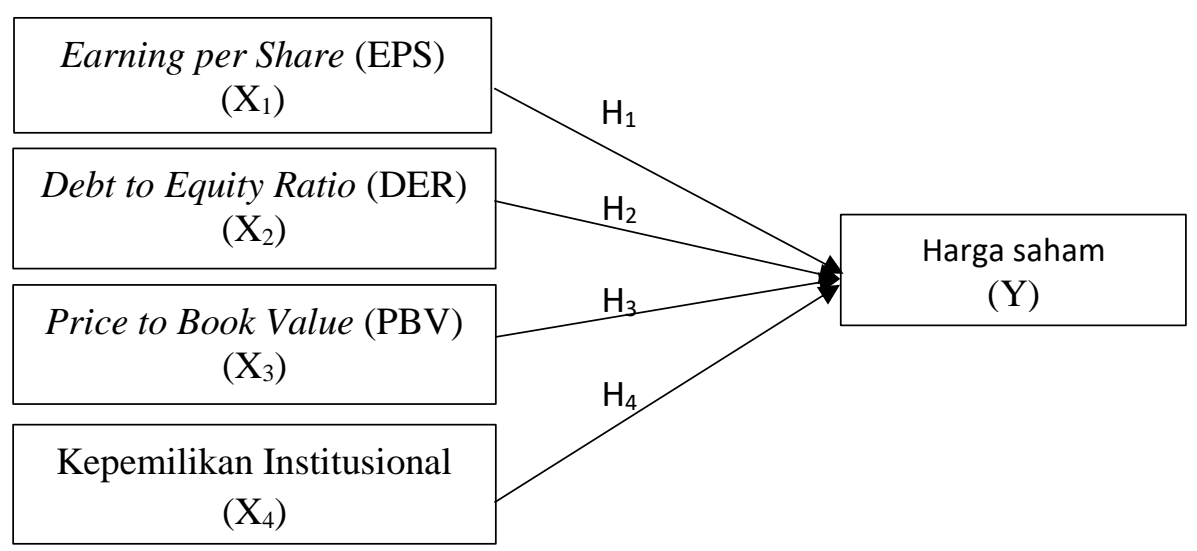

\section{METODE PENELITIAN}

\section{Operasionalisasi Variabel}

Berdasarkan pada masalah dan hipotesis yang akan diuji, maka variabel-variabel yang akan diteliti yakni sebagai berikut:

Tabel 3.1

Ringkasan Operasional Variabel

\begin{tabular}{|c|c|c|c|}
\hline Variabel & Sub Variabel & Indikator & Skala \\
\hline Dependen & $\begin{array}{l}\text { Harga Saham } \\
\text { (Y) }\end{array}$ & Closing Price & Nominal \\
\hline \multirow{4}{*}{ Independen } & $\begin{array}{c}\text { Earning per Share (EPS) } \\
\left(\mathrm{X}_{1}\right)\end{array}$ & $\frac{\text { earning after tax }}{\text { total outstanding share }}$ & Rasio \\
\hline & $\begin{array}{l}\text { Debt to Equity Ratio (DER) } \\
\left(\mathrm{X}_{2}\right)\end{array}$ & $\frac{\text { total debt }}{\text { total equity }}$ & Rasio \\
\hline & $\begin{array}{c}\text { Price to Book Value (PBV) } \\
\left(\mathrm{X}_{3}\right)\end{array}$ & $\frac{\text { price per share }}{\text { book value per share }}$ & Rasio \\
\hline & $\begin{array}{l}\text { Kepemilikan Institusional } \\
\qquad\left(\mathrm{X}_{4}\right)\end{array}$ & $\frac{\text { kepemilikan Institusional }}{\text { total saham yang beredar }}$ & Rasio \\
\hline
\end{tabular}

\section{Jenis dan sumber data}

Pada penelitian ini menggunakan data sekunder yaitu berupa laporan keuangan dan laporan tahunan. Dalam penelitian ini, data sekunder diperoleh website Bursa Efek Indonesia (BEI), yaitu http://www.idx.co.id dan juga yang tersedia di Pojok Bursa Efek Indonesia Fakultas Ekonomi dan Bisnis Universitas Pancasila. 


\section{Populasi dan Sampel}

Populasi dalam penelitian ini adalah perusahaan yang masuk dalam sektor infrastruktur, utilitas, dan transportasi sebanyak 48 perusahaan yang terdaftar di Bursa Efek Indonesia (BEI) selama periode 2014-2018. Teknik yang dilakukan dalam pengambilan sampel penelitian ini adalah purposive sampling. Adapun kriteria-kriteria yang digunakan dalam penelitian ini sebagai berikut:

a. Perusahaan jasa sektor infrastruktur, utilitas, dan transportasi yang terdaftar dan tidak delisting ataupun relisting (masuk kembali) di Bursa Efek Indonesia (BEI) selama periode penelitian.

b. Perusahaan yang menerbitkan annual report pada tahun 2014-2018.

c. Perusahaan pada periode pengamatan, sahamnya aktif diperdagangkan di BEI bila tidak aktif akan mengganggu proses analisis.

d. Perusahaan yang memiliki data yang diduga berdistribusi tidak normal (outlier).

\section{Rancangan Analisis dan Uji Hipotesis}

\section{Statistik Deskriptif}

Statistik deskriptif adalah statistik yang digunakan untuk menganalisa data dengan cara mendeskripsikan atau menggambarkan data yang telah terkumpul sebagaimana adanya tanpa bermaksud membuat kesimpulan yang berlaku untuk umum atau generalisasi (Sugiyono, 2017:238).

\section{Uji Asumsi Klasik}

Uji Normalitas bertujuan untuk menguji apakah dalam sebuah model regresi, varibel independent dan variabel dependen atau keduanya telah terdistribusi secara normal atau tidak. Model regresi yang baik yaitu yang memiliki distribusi data normal atau mendekati normal (Ghozali, 2013: 145). Pengujian normalitas residual yang banyak digunakan adalah uji JarqueBera (JB).

Uji Multikolonieritas bertujuan untuk menguji apakah model regresi ditemukan adanya korelasi yang tinggi antar variabel independen (Ghozali, 2017:71).

Dalam melakukan pengujian heteroskedastisitas pada analisis data panel menggunakan uji glejser dengan meregresikan variabel-varibel bebas terhadap residual absolut. Uji glejser hanya berlaku pada Fixed Effect Model (FEM) dan Common Effect Model (CEM). Apabila nilai probabilitas lebih besar dari 0,05 maka terbebas dari asumsi heterokedastisitas. 


\section{Analisis Model Regresi Data Panel}

Penelitian dengan regresi data panel ini digunakan untuk mengetahui ada atau tidaknya pengaruh variabel-variabel independen (bebas), yaitu Earning per Share (EPS), Debt to Equity Ratio (DER), Price to Book Value (PBV), dan Kepemilikan Institusional (KI) terhadap variabel dependen (terikat), yaitu harga saham.

Persamaan regresi dalam penelitian ini adalah :

$\mathrm{Y}=\mathrm{a}+\beta \mathrm{X} 1+\beta \mathrm{X} 2+\beta \mathrm{X} 3+\beta \mathrm{X} 4+\mathrm{e}$

Keterangan :

$\mathrm{Y}=$ Harga Saham (Closing Price)

$\mathrm{a}=$ Konstanta

$\beta=$ Koefisien Regresi

$\mathrm{X}_{1}=$ Earning per Share $($ EPS)

$\mathrm{X}_{2}=$ Debt to Equity Ratio (DER)

$\mathrm{X}_{3}=$ Price to Book Value $(\mathrm{PBV})$

$\mathrm{X}_{4}=$ Kepemilikan Institusional (KI)

$\mathrm{e}=$ Error

\section{Pengujian Model}

Untuk menentukan model regresi data panel yang tepat untuk digunakan dalam analisis regresi data panel, terdapat tiga metode yang dapat dilakukan, yaitu sebagai berikut (Prawoto, 2017:277) :

a. Uji signifikansi common effect atau fixed effect (Uji Chow)

Hipotesis uji chow adalah :

$H_{0}$ : Common Effect Model

$H_{1}$ : Fixed Effect Model

Pedoman yang akan digunakan dalam pengambilan kesimpulan uji chow adalah sebagai berikut :

Jika nilai probability cross-section chi-square $<\alpha(5 \%)$, maka $\mathrm{H}_{0}$ ditolak, yang berarti model fixed effect yang dipilih. Apabila nilai probability cross-section chi-square $>\alpha(5 \%)$, maka $\mathrm{H}_{0}$ diterima, yang berarti model common effect yang dipilih.

b. Uji signifikansi fixed effect atau random effect (Uji Haussman)

Hipotesis dalam pengujian uji Hausman yaitu: 


\section{$H_{0}:$ Random Effect Model}

$H_{1}:$ Fixed Effect Model

Pedoman yang akan digunakan dalam pengambilan kesimpulan uji chow adalah sebagai berikut :

Jika probability cross-section chi-square $<\alpha(5 \%)$, maka $\mathrm{H}_{0}$ ditolak, yang berarti model fixed effect yang dipilih. Apabila nilai probability cross-section chi-square $>\alpha(5 \%)$, maka $\mathrm{H}_{0}$ diterima, yang berarti model random effect yang dipilih.

\section{c. Uji Lagrange Multiplier (LM)}

metode yang paling tepat digunakan.

$\mathrm{H}_{0}=$ Common Effect Model (CEM)

$\mathrm{H}_{1}=$ Random Effect Model $(\mathrm{REM})$

Adapun pedoman yang digunakan dalam pengambilan kesimpulan uji LM berdasarkan metode Breusch-Pagan adalah sebagai berikut :

Jika nilai Cross-Section Breusch-Pagan $<\alpha(5 \%)$, maka $\mathrm{H}_{0}$ ditolak, yang berarti model random effect yang dipilih. Apabila nilai Cross-section Breusch-Pagan $>\alpha(5 \%)$, maka $\mathrm{H}_{0}$ diterima, yang berarti model common effect yang dipilih.

\section{Teknik Pengujian Hipotesis}

\section{Uji F-Statistik (Uji Kelayakan Model)}

Uji F-Statistik merupakan uji kelayakan model yaitu untuk mengetahui apakah model regresi yang digunakan tersebut layak atau tidak layak. Taraf signifikansi yang ditetapkan dalam penelitian ini adalah $5 \%(\alpha=0,05)$.

Uji Signifikansi Parameter Individual (Uji $t$ ) pada dasarnya bertujuan untuk menunjukkan seberapa jauh pengaruh satu variabel penjelas atau independen secara individual dalam menerangkan variabel dependen (Ghozali, 2013:98).

Uji Koefisien Determinasi $\left(\mathrm{R}^{2}\right)$ pada dasarnya mengukur sebarapa jauh kemampuan model dalam menerangkan variasi variabel dependen (Ghozali, 2013:87). 


\section{P ISSN 2622-7177 \\ [ACCOUNTING GLOBAL JOURNAL] E ISSN 2623-1778}

4. HASIL DAN PEMBAHASAN

Hasil Pengujian Statistik Deskriptif

Tabel 4.3

Analisis Statistik Deskriptif

\begin{tabular}{lcccccc}
\hline \hline & HS & C & EPS & DER & PBV & KI \\
\hline \hline Mean & 6.527532 & 1.000000 & 3.687987 & 1.387078 & 2.394740 & 0.666883 \\
Median & 6.560000 & 1.000000 & 3.825000 & 0.970000 & 1.235000 & 0.700000 \\
Maximum & 9.610000 & 1.000000 & 6.770000 & 13.54000 & 22.17000 & 0.990000 \\
Minimum & 3.910000 & 1.000000 & -2.300000 & -1.750000 & -1.690000 & 0.110000 \\
Std. Dev. & 1.530351 & 0.000000 & 1.718537 & 1.873925 & 3.483649 & 0.189186 \\
Observations & 154 & 154 & 154 & 154 & 154 & 154
\end{tabular}

Sumber : Data yang telah diolah

\section{Uji Normalitas}

Gambar 4.1

Hasil Uji Normalitas

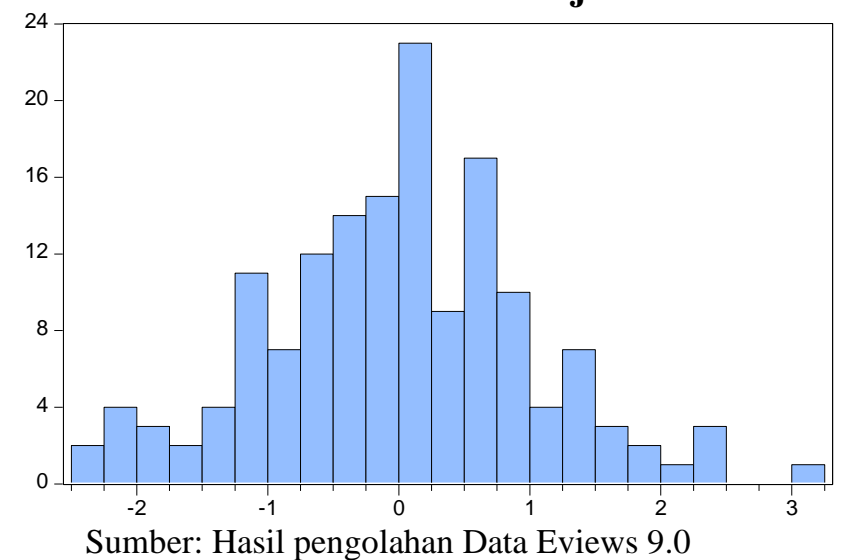

Series: Standardized Residuals

Sample 20142018

Observations 154

Mean 4.73e-16

Median $\quad 0.021024$

Maximum 3.079629

Minimum $\quad-2.336180$

Std. Dev. $\quad 1.012925$

Skewness $\quad 0.095707$

Kurtosis $\quad 3.199788$

Jarque-Bera $\quad 0.491226$

$\begin{array}{ll}\text { Probability } & 0.782225\end{array}$

Berdasarkan tabel di atas, diketahui nilai probability sebesar $0.782225>0.05$, maka dapat disimpulkan bahwa data terdistribusi normal.

\section{Uji Multikolinieritas}

Tabel 4.4

Uji Multikolinieritas

\begin{tabular}{ccccc}
\hline \hline & EPS & DER & PBV & KI \\
\hline \hline EPS & 1.000000 & 0.165392 & 0.136812 & -0.059599 \\
DER & 0.165392 & 1.000000 & 0.618854 & -0.095113 \\
PBV & 0.136812 & 0.618854 & 1.000000 & -0.045780 \\
KI & -0.059599 & -0.095113 & -0.045780 & 1.000000
\end{tabular}

Sumber: Data yang telah diolah 


\section{P ISSN 2622-7177 \\ [ACCOUNTING GLOBAL JOURNAL] E ISSN 2623-1778}

Hasil pengujian multikolinearitas di atas menunjukkan bahwa dalam model regresi antar variabel-variabel independen Earning per Share (EPS), Debt to Equity Ratio (DER), Price to Book Value (PBV), Kepemilikan Institusional (KI) tidak terjadi multikolinearitas. Hal ini dapat dilihat pada masing-masing variabel tersebut yang nilainya lebih kecil dari 0,80 .

\section{Uji Heteroskedastisitas}

Tabel 4.5

Uji Heteroskedastisitas

\begin{tabular}{crrrr}
\hline \hline Variable & Coefficient & Std. Error & t-Statistic & Prob. \\
\hline \hline C & 1.167503 & 0.226588 & 5.152542 & 0.0000 \\
EPS & -0.023314 & 0.030327 & -0.768760 & 0.4433 \\
DER & 0.030857 & 0.035151 & 0.877864 & 0.3814 \\
PBV & -0.031917 & 0.018768 & -1.700639 & 0.0911 \\
KI & -0.395548 & 0.272698 & -1.450501 & 0.1490 \\
\hline \hline
\end{tabular}

Sumber: Data yang telah diolah

Dari tabel 4.5 di atas dapat dilihat bahwa pengujian heteroskedastisitas dapat dilihat bahwa probability pada masing-masing variabel independen $(0,4433 ; 0,3814 ; 0,0911 ; 0,1490)$ lebih besar dari 0,05. Sehingga dapat disimpulkan data dalam variabel penelitian ini tidak terdapat heteroskedastisitas pada model penelitian ini.

Uji Chow, Uji Haussman, dan Uji Langrange Multiplier

Tabel 4.9

Hasil Uji Chow

\begin{tabular}{lrrr}
\hline \hline Effects Test & Statistic & d.f. & Prob. \\
\hline \hline Cross-section F & 4.727818 & $(30,119)$ & 0.0000 \\
Cross-section Chi-square & 120.853465 & 30 & 0.0000 \\
\hline \hline
\end{tabular}

Sumber: Data yang telah diolah

Tabel 4.10

Hasil Uji Haussman

\begin{tabular}{lrrr}
\hline \hline Test Summary & Chi-Sq. Statistic & Chi-Sq. d.f. & Prob. \\
\hline \hline Cross-section random & 9.335315 & 4 & 0.0532 \\
\hline \hline
\end{tabular}

Sumber: Data yang telah diolah 
Tabel 4.11

Hasil Uji Lagrange Multiplier

\begin{tabular}{lccc}
\hline \hline & & Test Hypothesis \\
& Cross-section & Bime & Both \\
\hline \hline Breusch-Pagan & $\begin{array}{l}41.32172 \\
(0.0000)\end{array}$ & $\begin{array}{l}0.000284 \\
(0.9866)\end{array}$ & $\begin{array}{l}41.32201 \\
(0.0000)\end{array}$
\end{tabular}

sumber: Data yang Telah Diolah

\section{Analisis Regresi Data Panel}

Tabel 4.12

Hasil Regresi Data Panel

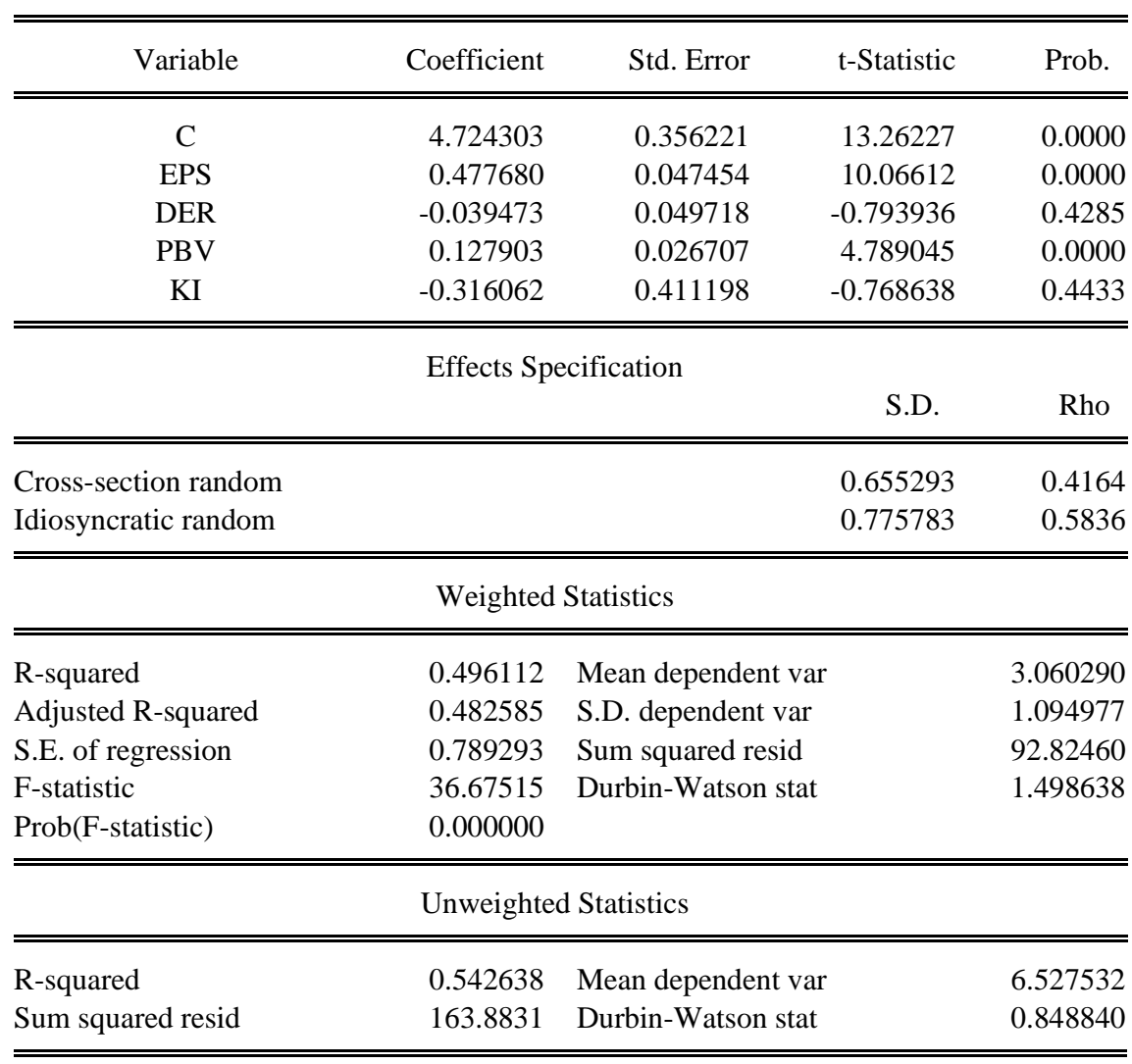

Data yang telah diolah

Sumber:

Persamaan regresinya adalah :

$\mathrm{Y}=4.724303+0.477680 \mathrm{X}_{1}-0.039473 \mathrm{X}_{2}+0.127903 \mathrm{X}_{3}-0.316062 \mathrm{X}_{4}+\mathrm{e}$

Dari model regresi tersebut dapat dijelaskan :

a. Nilai konstanta sebesar 4.724303 artinya adalah apabila Earning per Share (EPS), Debt to

Equity Ratio (DER), Price to Book Value (PBV), dan Kepemilikan Institusional (KI) adalah

0, maka Harga Saham sebesar 4.724303. 
b. Nilai koefisien regresi Earning per Share (EPS) bernilai positif sebesar 0.477680 artinya adalah apabila Earning per Share (EPS) meningkat satu satuan, maka Harga Saham akan meningkat sebesar 0.477680 dengan asumsi variabel independent lainnya tetap.

c. Nilai koefisien regresi Debt to Equity Ratio (DER) bernilai negatif sebesar 0.039473 artinya adalah apabila DER meningkat satu satuan, maka Harga Saham akan menurun sebesar 0.039473 dengan asumsi variabel independent lainnya tetap.

d. Nilai koefisien regresi Price to Book Value (PBV) bernilai positif sebesar 0.127903 artinya adalah apabila PBV meningkat satu satuan, maka harga saham akan meningkat sebesar 0.127903 dengan asumsi variabel independen lainnya tetap.

e. Nilai koefisien regresi Kepemilikan Institusional (KI) bernilai negatif sebesar 0.316062 artinya apabila KI meningkat satu satuan, maka harga saham akan menurun sebesar 0.316062 dengan asumsi variabel independen lainnya tetap.

\section{Uji Simultan (Uji F)}

Tabel 4.13

Uji F-Statistik

\begin{tabular}{|l|l|}
\hline F-statistic & 36.67515 \\
\hline Prob(F-statistic) & 0.000000 \\
\hline
\end{tabular}

Sumber: Hasil Olah Data Eviews 9.0

Berdasarkan hasil pengujian pada tabel 4.13 dapat dilihat nilai $\mathrm{F}$ hitung sebesar 36.67515 dengan nilai F-Signifikansi sebesar 0.000000 lebih kecil dari 0.05 .

\section{Uji Parsial (Uji t)}

Tabel 4.14

Hasil Uji t (Parsial)

\begin{tabular}{crrrr}
\hline \hline Variable & Coefficient & Std. Error & t-Statistic & Prob. \\
\hline \hline C & 4.724303 & 0.356221 & 13.26227 & 0.0000 \\
EPS & 0.477680 & 0.047454 & 10.06612 & 0.0000 \\
DER & -0.039473 & 0.049718 & -0.793936 & 0.4285 \\
PBV & 0.127903 & 0.026707 & 4.789045 & 0.0000 \\
KI & -0.316062 & 0.411198 & -0.768638 & 0.4433 \\
\hline \hline
\end{tabular}

Sumber: Data yang telah diolah 
Berdasarkan hasil diatas ditarik kesimpulan sebagai berikut :

a. Dari hasil regresi yang didapat bahwa Earning per Share (EPS) mempunyai nilai signifikansi $0.0 .0000<0.05$, sehingga dapat disimpulkan $\mathrm{H}_{1}$ diterima yang berarti bahwa variabel Earning per Share (EPS) terdapat pengaruh signifikan terhadap harga saham pada perusahaan jasa sektor infrastruktur, utilitas, dan transportasi yang terdaftar di Bursa Efek Indonesia tahun 2014-2018.

b. Dari hasil regresi yang didapat bahwa Debt to Equity Ratio (DER) mempunyai nilai signifikansi $0.4285>0.05$, sehingga dapat disimpulkan $\mathrm{H}_{2}$ diterima yang berarti bahwa variabel Debt to Equity Ratio (DER) tidak terdapat pengaruh signifikan terhadap harga saham pada perusahaan jasa sektor infrastruktur, utilitas, dan transportasi yang terdaftar di Bursa Efek Indonesia tahun 2014-2018.

c. Dari hasil regresi yang didapat bahwa Price to Book Value (PBV) mempunyai nilai signifikansi $0.0000<0.05$, sehingga dapat disimpulkan $\mathrm{H}_{3}$ diterima yang berarti bahwa variabel Price to Book Value (PBV) terdapat pengaruh signifikan terhadap harga saham pada perusahaan jasa sektor infrastruktur, utilitas, dan transportasi yang terdaftar di Bursa Efek Indonesia tahun 2014-2018.

d. Dari hasil regresi yang didapat bahwa Kepemilikan Institusional (KI) mempunyai nilai signifikansi $0.4433>0.05$, sehingga dapat disimpulkan $\mathrm{H}_{4}$ diterima yang berarti bahwa variabel Kepemilikan Institusional (KI) tidak terdapat pengaruh signifikan terhadap harga saham pada perusahaan jasa sektor infrastruktur, utilitas, dan transportasi yang terdaftar di Bursa Efek Indonesia tahun 2014-2018.

\section{Koefisien Determinasi $\left(\mathbf{R}^{2}\right)$}

Tabel 4.15

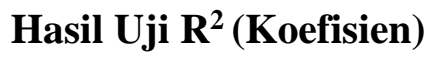

\begin{tabular}{|l|c|}
\hline$R$-squared & 0.496112 \\
\hline Adjusted $R$-squared & 0.482585 \\
\hline \multicolumn{2}{|c|}{ Sumber: Data yang telah diolah } \\
\hline
\end{tabular}


Hal ini menunjukkan bahwa $48.25 \%$ dari variabel Earning per Share (EPS), Debt to Equity Ratio (DER), Price to Book Value (PBV) dan Kepemilikan Institusional (KI) mampu menjelaskan variabel Harga Saham. Sedangkan sisanya sebesar 51.75\% dijelaskan oleh faktor lain di luar model penelitian ini.

\section{Pembahasan}

\section{Pengaruh Earning per Share (EPS) terhadap harga saham}

variabel Earning per Share (EPS) terdapat pengaruh signifikan terhadap harga saham. Hal ini menunjukkan bahwa Earning per Share (EPS) merupakan salah satu indikator yang penting dan menjadi perhatian bagi calon investor untuk memutuskan berinvestasi di pasar modal. Semakin tinggi nilai Earning per Share (EPS) maka semakin tinggi minat investor untuk berinvestasi karena makin besar laba yang diproleh oleh pemegang saham menyebabkan harga saham di suatu perusahaan tersebut akan cenderung meningkat.

\section{Pengaruh Debt to Equity Ratio (DER) terhadap harga saham}

Debt to Equity Ratio (DER) memberikan informasi tentang kemampuan perusahaan dalam memenuhi kewajiban perusahaan baik hutang jangka pendek maupun jangka panjang, sehingga sebagian investor beranggapan bahwa perusahaan yang mempunyai Debt to Equity Ratio (DER) yang tinggi akan membebani keuangan perusahaan dan juga merugikan investor yang sudah menanamkan modalnya. Namun demikian beberapa investor justru memandang bahwa perusahaan yang tumbuh pasti akan memerlukan hutang sebagai dana tambahan untuk memenuhi pendanaan pada perusahaan yang tumbuh. Perusahaan tersebut memerlukan banyak dana operasional yang tidak mungkin dapat dipenuhi hanya dari modal sendiri yang dimiliki perusahaan.

\section{Pengaruh Price to Book Value (PBV) terhadap harga saham}

Semakin besar rasio Price to Book Value (PBV) semakin tinggi perusahaan dinilai oleh investor dibandingkan dana yang telah di investasikan di perusahaan. Penilaian perusahaan oleh investor akan mempengaruhi keputusan investasi, karena investor akan berinvestasi diperusahaan yang tingkat kinerjanya baik. Minat investor terhadap harga saham perusahaan yang tingkat kinerjanya baik akan berpengaruh terhadap naiknya harga saham perusahaan.

\section{Pengaruh Kepemilikan Institusional (KI) terhadap Harga Saham}

Investor Institusional mayoritas memiliki kecenderungan untuk berkompromi atau berpihak kepada manajemen dan mengabaikan kepentingan pemegang saham minoritas. 
Anggapan bahwa manajemen sering mengambil tindakan atau kebijakan yang non-optimal dan cenderung mengarah pada kepentingan pribadi mengakibatkan strategi aliansi antara investor institutional dengan pihak manajemen ditanggapi negatif oleh pasar. Hal ini tentunya berdampak pada penurunan harga saham perusahaan dipasar modal.

\section{SIMPULAN DAN SARAN}

\section{KESIMPULAN}

Berdasarkan hasil analisis data dan pembahasan penelitian yang dilakukan dapat diambil kesimpulan yang berkaitan dengan variabel Earning per Share (EPS), Debt to Equity Ratio (DER), Price to Book Value (PBV), dan Kepemlikan Institusional (KI) terhadap Harga Saham adalah sebagai berikut:

a. Hasil penelitian ini menunjukkan bahwa Earning per Share (EPS) berpengaruh signifikan terhadap harga saham. Hal ini karena semakin tinggi nilai Earning per Share (EPS) maka semakin tinggi minat investor untuk berinvestasi dan menyebabkan harga saham perusahaan tersebut naik.

b. Hasil penelitian ini menunjukkan bahwa Debt to Equity Ratio (DER) tidak berpengaruh signifikan terhadap harga saham. Hal ini karena beberapa investor memandang bahwa perusahaan yang sedang tumbuh akan memerlukan banyak dana operasional yang tidak mungkin dapat dipenuhi dari modal yang dimiliki oleh perusahaan sehingga Debt to Equity Ratio (DER) tidak signifikan mempengaruhi harga saham.

c. Hasil penelitian ini menunjukkan bahwa Price to Book Value (PBV) berpengaruh signifikan terhadap harga saham. Hal ini karena semakin tinggi Price to Book Value (PBV) semakin tinggi tingkat kepercayaan pasar terhadap prospek perusahaan, maka akan menjadi daya tarik bagi investor untuk membeli saham tersebut, sehingga harga saham perusahaan akan meningkat.

d. Hasil penelitian ini menunjukkan bahwa Kepemilikan Institusional (KI) tidak berpengaruh signifikan terhadap harga saham. Hal ini karena keberpihakan investor institusional kepada manajemen sehingga manajer dapat mengambil keputusan dengan leluasa di dalam pengelolaan manajemen perusahaan ditanggapi negatif oleh pasar dan berpengaruh terhadap penurunan harga saham. 


\section{SARAN}

Adapun saran yang dapat diberikan oleh peneliti dapat digunakan sebagai bahan pertimbangan bagi pembaca atau untuk penelitian selanjutnya, adalah :

a. Bagi peneliti selanjutnya, perlu menambah variabel-variabel tidak hanya rasio keuangan tetapi juga indikator-indikator lainnya yang dapat mempengaruhi saham.

b. Bagi investor dan calon inverstor yang akan menamkan modalnya, agar dapat menganalisis laporan keuangan perusahaan sebelum menanamkan modalnya.

c. Bagi perusahaan, diharapkan agar mengoptimalkan kinerjanya sehingga menghasilkan laporan keuangan yang baik agar dapat menarik investor untuk menanamkan modalnya sehingga dapat meningkatkan harga saham perusahaan.

\section{DAFTAR PUSTAKA}

Akbar, P. S., \& Husnaini, U. (2011). Metodelogi Penelitian Social. Jakarta: Bumi Aksara.

Basuki, A. T., \& Prawoto, N. (2017). Analisis Regresi dalam Penelitian Ekonomi dan Bisnis: dilengkapi Aplikasi SPSS \& EVIEWS. Depok: PT Rajagrafindo Persada.

Fahmi, I. (2012). Pengantar Pasar Modal. Bandung: Alfabeta.

Fahmi, I. (2012). Manajemen Investasi: Teori dan Soal/Jawab. Jakarta: Salemba Empat.

Ghozali, I. (2013). Aplikasi Analisis Multivariate dan Ekonometrika: Teori, Konsep, ,dan Aplikasi dengan Eviews 8. Semarang: Universitas Diponegoro.

Halim, A. (2018). Analisis Investasi dan Aplikasinya: dalam Aset Keuangan dan Aset Riil. Jakarta: Salemba Empat.

Hartono, J. (2008). Teori Portofolio dan Analisis Investasi Edisi Kelima. Yogyakarta: BPFE. Hery. (2014). Analisis Kinerja Manajemen. Jakarta: PT Grasindo.

Nugrahanti, Y. W., \& Ardy, Y. (2013). Pengaruh Struktur Kepemilikan Terhadap Profitabiitas Perusahaan Manufaktur di Indonesia. Jurnal Akuntansi dan Keuangan Volume 15 , Universitas Kristen Satya Wacana.

Siswoyo, S. (2013). Analisis Fundamental dan Teknikal Untuk Profit Lebih Maksimal. Jakarta: PT Gramedia.

Sugiyono. (2017). Metode Penelitian Kuantitatif, Kualitatif, dan R\&D. Bandung: Alfabeta.

Sunariyah. (2011). Pengantar Pengetahuan Pasar Modal. Yogyakarta: UPP STIM YKPN.

Sutedi, A. (2011). Good Corporate Governance. Jakarta: Sinar Grafika. 
Syamsudin, L. (2009). Manajemen Keuangan Perusahaan. Jakarta: PT Raja Grafindo Persada.

Tandelilin, E. (2010). Analisis Investasi dan Manajemen Portofolio. Yogyakarta: BPFE.

Walsh, C. (2004). Key Management Ratio. Jakarta: Erlangga.

Zulfikar. (2016). Pengantar Pasar Modal Dengan Pendekatan Statistika. Yogyakarta: Deepublish. 